Full length article

\title{
Bacteria-responsive multilayer coatings comprising polycationic nanospheres for bacteria biofilm prevention on urinary catheters
}

\author{
Antonio Francesko a,1, Margarida M. Fernandes ${ }^{a, 1}$, Kristina Ivanova ${ }^{a}$, Sara Amorim ${ }^{\text {b,c }}$, Rui L. Reis ${ }^{\text {b,c }}$, \\ Iva Pashkuleva ${ }^{\mathrm{b}, \mathrm{c}}$, Ernest Mendoza ${ }^{\mathrm{d}}$, Annett Pfeifer $^{\mathrm{e}}$, Thomas Heinze $^{\mathrm{e}}$, Tzanko Tzanov ${ }^{\mathrm{a}, *}$ \\ ${ }^{a}$ Grup de Biotecnologia Molecular i Industrial, Department of Chemical Engineering, Universitat Politècnica de Catalunya, Spain

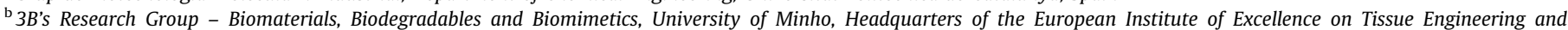 \\ Regenerative Medicine, Avepark, Zona Industrial da Gandra, 4805-017 Barco, Guimarães, Portugal \\ 'ICVS/3B's - PT Government Associate Laboratory, Braga/Guimarães, Portugal \\ ${ }^{\mathrm{d}}$ Grup de Nanomaterials Aplicats, Centre de Recerca en Nanoenginyeria, Universitat Politècnica de Catalunya, Spain \\ ${ }^{\mathrm{e}}$ Center of Excellence for Polysaccharide Research, Institute of Organic Chemistry and Macromolecular Chemistry, Friedrich Schiller University of Jena, Germany
}

\section{A R T I C L E I N F O}

\section{Article history:}

Received 27 August 2015

Received in revised form 13 January 2016

Accepted 18 January 2016

Available online 19 January 2016

\section{Keywords:}

Polycation

Nanospheres

Layer-by-layer fabrication

Antibacterial surfaces

Biofilm inhibition

\begin{abstract}
A B S T R A C T
This work reports on the development of infection-preventive coatings on silicone urinary catheters that contain in their structure and release on demand antibacterial polycationic nanospheres. Polycationic aminocellulose conjugate was first sonochemically processed into nanospheres to improve its antibacterial potential compared to the bulk conjugate in solution $\left(A C_{S o l}\right)$. Afterward the processed aminocellulose nanospheres $\left(A C_{N S s}\right.$ ) were combined with the hyaluronic acid (HA) polyanion to build a layer-by-layer construct on silicone surfaces. Although the coating deposition was more effective when HA was coupled with $\mathrm{AC}_{\mathrm{Sol}}$ than with $\mathrm{AC}_{\mathrm{NSs}}$, the $\mathrm{AC}_{\mathrm{NSs}}$-based coatings were thicker and displayed smoother surfaces due to the embedment of intact nanospheres. The antibacterial effect of $\mathrm{AC}_{\mathrm{NSs}}$ multilayers was $40 \%$ higher compared to $\mathrm{AC}_{\mathrm{Sol}}$ coatings. This fact was further translated into more effective prevention of Pseudomonas aeruginosa biofilm formation. The coatings were stable in the absence of bacteria, whereas their disassembling occurred gradually during incubation with $P$. aeruginosa, and thus eradicate the biofilm upon release of antibacterial agents. Only 5 bilayers of $\mathrm{HA} / \mathrm{AC}_{\mathrm{NSs}}$ were sufficient to prevent the biofilm formation, in contrast to the 10 bilayers of $A_{\text {Sol }}$ required to achieve the same effect. The antibiofilm efficiency of $\left(\mathrm{HA} / \mathrm{AC}_{\mathrm{NSs}}\right)_{10}$ multilayer construct built on a Foley catheter was additionally validated under dynamic conditions using a model of the catheterized bladder in which the biofilm was grown during seven days.
\end{abstract}

\section{Statement of Significance}

Antibacterial layer-by-layer coatings were fabricated on silicone that efficiently prevents Pseudomonas aeruginosa biofilm formation during time beyond the useful lifetime of the currently employed urinary catheters in medical practice. The coatings are composed of intact, highly antibacterial polycationicnanospheres processed from aminated cellulose and bacteria-degrading glycosaminoglycan hyaluronic acid. The importance of incorporating nanoscale structures within bacteria-responsive surface coatings to impart durable antibacterial and self-defensive properties to the medical indwelling devices is highlighted.

(c) 2016 Acta Materialia Inc. Published by Elsevier Ltd. All rights reserved.

\footnotetext{
* Corresponding author at: Grup de Biotecnologia Molecular i Industrial, Department of Chemical Engineering, Universitat Politècnica de Catalunya, Rambla Sant Nebridi 22, 08222 Terrassa, Spain.

E-mail address: tzanko.tzanov@upc.edu (T. Tzanov).

1 These authors contributed equally to the work.
}

\section{Introduction}

Indwelling urinary catheters routinely employed in clinical practice are among the medical devices that are most susceptible to microbial contaminations. Pathogens present at the site of catheter insertion or in the urine attach easily to the catheter surface and colonize it progressively to establish a mature biofilm. The bacterial cells encased in a biofilm are upto 1000 times more 
resistant to host defense mechanisms and conventional antibiotic treatments when compared to planktonic cells [1]. Once established, the biofilm serves as a reservoir that maintains the infection in the host. Consequently, their formation causes difficult-to-treat infections, unnecessary distress to patients and delays in recovery. Biofilm-associated urinary tract infections account for $\sim 40 \%$ of all hospital-acquired infections [2], defining an urgent need for the development of novel, engineered catheter surfaces able to prevent the biofilm formation.

One approach to prevent biofilm formation on medical devices is their surface functionalization with broad-spectrum antibacterial agents. However, the substantial evolutionary stress that antimicrobials exert on bacteria ultimately results in the emergence of a multi-drug resistance species. Significant efforts are being made to design novel antibacterial surfaces limiting the bacterial colonization without promoting bacterial resistance. Existing antibiofilm materials show different efficiency toward single and multi-species biofilms and can be categorized as: (i) engineered nano- and micro-topography surfaces that inhibit bacteria adhesion [3,4], (ii) surfaces with immobilized antibiotics that kill bacteria upon adhesion [5], and (iii) biocide leaching surfaces [6,7]. All these features are imparted to the device surface using different functionalization approaches, ensuring a minimal loss of the biological functions of the deposited compound. For example, layer-by-layer (LbL) assembly of polyelectrolytes is an easy, versatile and cost-effective method for building bioactive coatings incorporating multiple modalities on a variety of surfaces. This technique is based on the alternating adsorption of oppositely charged polyions and has been used for surface immobilization of a broad range of biomacromolecules [8,9], enzymes [10], drugs [11], and nanoparticles [12], without causing structural changes that could alter their efficacy. In an attempt to engineer bioresponsive microenvironments that prevent the biofilm formation on silicone surfaces, we previously employed the LbL method to encase acylase enzyme, which quenches bacteria quorum sensing signals and interrupts their communication and the biofilm growth [13].

The incorporation of triggers in the coatings to release antibacterial agents upon external stimuli is an additional function that provides a therapeutic dose while avoiding systemic toxicity. Triggers such as pH [14], electric field [15] and temperature [16] have been frequently reported as stimuli for the release of therapeutic agents. Recently, bacteria themselves and their metabolites have been proposed as polymer hydrolyzing organisms, which can be turned into a robust trigger for antibacterial drug release in a self-defense principle [17,18]. For example, Pseudomonas aeruginosa ( $P$. aeruginosa), a clinically relevant pathogen in most urinary tract infections, is known to produce a variety of cell-associated and extracellular metabolites including enzymes and toxins as factors for its pathogenicity [19]. One of the toxins, pyocianin, is able to degrade glycosaminoglycans (commonly used in LbL deposition) by a non-enzymatic mechanism due to its auto-oxidation properties [20]. As a redox active virulence factor, pyocianin exists in either oxidized or reduced form, the latter being an unstable free radical, which oxidizes rapidly with molecular oxygen [21]. The auto-oxidation leads to the formation of reactive oxidative species (ROS) such as superoxide $\left(\mathrm{O}_{2}^{-}\right)$or hydrogen peroxide $\left(\mathrm{H}_{2} \mathrm{O}_{2}\right)$, among others, capable of depolymerizing glycosaminoglycans, e.g. hyaluronic acid (HA) [22]. ROS are actually known for their oxidative degradation of different biomacromolecules (proteins, lipids and polysaccharides) [23]. The next biomedical challenge is to take advantage of such a degradation mechanism by integrating the triggers into bio-responsive coatings that will gradually release therapeutic doses of antibacterial agents and will be effective over long periods of time. LbL coatings are suitable constructs for achieving such responsiveness due to their ability to release an agent in sequential events, i.e. after the degradation of each glycosaminoglycan layer.

Cationic compounds are underutilized biocides [24] that effectively reduce bacterial count on a surface of interest without the use of antibiotics [25], thereby having great potential as antibacterial agents to reduce the risk of resistance development. Contactkilling surfaces could be easily built by LbL deposition of structures with a dense cationic charge to disrupt bacterial cell membranes and impart antimicrobial activity to a material [26]. Electrostatic binding between the cationic molecules and the intrinsically anionic bacterial cell wall induces the damage of the latter leading to cell death. This specific mechanism of action is believed to diminish the possibility of developing new resistant strains because the bacterial membrane is highly evolutionary conserved and unlikely to be changed by a single gene mutation.

Recently, we reported that cationic nanostructures in a dispersion, i.e. aminocellulose nanospheres $\left(\mathrm{AC}_{\mathrm{NSs}}\right)$, possess improved antibacterial properties via a membrane disturbing capacity compared to aminocellulose in solution $\left(\mathrm{AC}_{\mathrm{sol}}\right)$ [27]. In the current study, we continue the investigation by building multilayer coatings incorporating $\mathrm{AC}_{\mathrm{NSs}}$ on silicone surfaces to efficiently eradicate bacteria and prevent the biofilm formation. Sonochemically-processed nanospheres obtained from the cationic conjugate, 6-deoxy-6-( $\omega$-aminoethyl) aminocellulose, were combined with the bacteria-degradable HA polyanion to engineer LbL coatings on silicone urinary catheters and evaluate their bacteria responsiveness and antibacterial/antibiofilm capacities against the medically relevant biofilm-associated infections of P. aeruginosa.

\section{Materials and methods}

\subsection{Materials and reagents}

Polydimethyl/vinylmethyl siloxane Foley urinary catheters designated according to ASTM D1418 and non-shaped strips from the same material as model surfaces were provided by Degania Silicone Ltd. (Israel). Biofilm forming bacterium P. aeruginosa (ATCC 10145) was obtained from American Type Culture Collection (LGC Standards S.L.U, Spain). Cationic derivative of cellulose, 6-deoxy-6( $\omega$-aminoethyl) aminocellulose (AC, $\sim 15 \mathrm{kDa}$ ), was synthesized from microcrystalline cellulose (Fluka, Avicel PH-101) via a tosyl cellulose intermediate [28], using a previously described procedure [29]. Negatively charged hyaluronic acid (HA) with average $\mathrm{Mw} \sim 750 \mathrm{kDa}$ was obtained from Lifecore Biomedical (USA) in the form of its sodium salt, and used as a counterion to AC. Live/ Dead BacLight kit (Molecular probes L7012) was purchased from Invitrogen, Life Technologies Corporation (Spain). All other chemical and microbiological reagents were purchased from Sigma-Aldrich unless otherwise specified.

\subsection{Methods}

\subsubsection{Preparation of $A C$ nanospheres}

Highly cationic $A C_{N S s}$ with sunflower oil as a lipid core were prepared by an adapted sonochemical method of Suslick [30], reported elsewhere for different kinds of biopolymers and their derivatives [31]. Briefly, the $\mathrm{pH}$ of the AC aqueous solution $(1 \mathrm{mg} / \mathrm{mL})$ was adjusted to 5.5 using $0.1 \mathrm{M} \mathrm{HCl}$. Then, a mixture of $70 \% \mathrm{AC}$ and $30 \%$ of commercial sunflower oil was prepared in a thermostated $\left(4^{\circ} \mathrm{C} \pm 0.5^{\circ} \mathrm{C}\right)$ sonochemical cell. The nanospheres were prepared using a Ti horn of a high-intensity Vibra-Cell VCX 750 ultrasonic processor (Sonics and Materials, Inc., USA), employing $20 \mathrm{kHz}$ at 35\% amplitude. The Ti horn was positioned at the aqueous-organic interface. An acoustic power of $\sim 0.5 \mathrm{~W} / \mathrm{cm}^{3}$ was 
applied for $3 \mathrm{~min}$ and the resulted suspension was partially cleaned from non-encapsulated oil by three consecutive centrifugations at $1500 \mathrm{rpm}$ for $15 \mathrm{~min}$.

\subsubsection{Assembling of multilayer coatings}

Multilayer coatings were assembled on silicone supports previously washed with sodium dodecyl sulfate (SDS), water and ethanol, and surface functionalized with amino groups by pretreatment with 3-(aminopropyl)triethoxysilane (APTES) to facilitate the deposition of the first negatively charged HA layer [13]. A solution of $\mathrm{HA}$ polyanion and a dispersion of $\mathrm{AC}_{\mathrm{NSs}}$ polycation were prepared with $0.15 \mathrm{M} \mathrm{NaCl}$ to reach final concentrations of $0.5 \mathrm{mg} /$ $\mathrm{mL}$. The $\mathrm{pH}$ was adjusted to 5.5 with $1 \mathrm{M} \mathrm{HCl}$ or $1 \mathrm{M} \mathrm{NaOH}$ aqueous solutions. The polyelectrolytes were alternately deposited using a multi-vessel automated dip coater system (KSV NIMA, Finland) on silicone starting with $\mathrm{HA}$ and finishing with $\mathrm{AC}_{\mathrm{NSs}}$ to form 5 , 10 and 100 bilayers. Each deposition lasted for $10 \mathrm{~min}$ and was followed by a $10 \mathrm{~min}$ rinsing step with $0.15 \mathrm{M} \mathrm{NaCl}, \mathrm{pH} 5.5$. The obtained multilayer coatings were named after the number of bilayers employed for their assembling: $\left(\mathrm{HA} / \mathrm{AC}_{\mathrm{NSs}}\right)_{5},\left(\mathrm{HA} / \mathrm{AC}_{\mathrm{NSs}}\right)_{10}$ and $\left(\mathrm{HA} / \mathrm{AC}_{\mathrm{NSs}}\right)_{100}$. Non-processed $\mathrm{AC}$ in solution and the same procedure for 5 and 10 bilayers were used to prepare the corresponding controls designated as $\left(\mathrm{HA} / \mathrm{AC}_{\mathrm{sol}}\right)_{5}$ and $\left(\mathrm{HA} / \mathrm{AC}_{\mathrm{sol}}\right)_{10}$.

The LbL build up was followed by a quartz crystal microbalance with dissipation (QCM-D, E4 system from Q-Sense, Sweden). The deposition was carried out on gold-coated AT-cut quartz crystals (QSX301, Q-Sense, Sweden) previously cleaned with 5:1:1 solution of $\mathrm{H}_{2} \mathrm{O}: \mathrm{NH}_{3}: \mathrm{H}_{2} \mathrm{O}_{2}$ at $80{ }^{\circ} \mathrm{C}$ for $10 \mathrm{~min}$, and amino functionalized with 11-amino-1-undecanethiol hydrochloride $\left(\mathrm{HS}\left(\mathrm{CH}_{2}\right)_{11} \mathrm{NH}_{2}\right)$ as described elsewhere [32]. Briefly, the crystals were immersed into $20 \mu \mathrm{M}$ ethanol solution of $\mathrm{HS}\left(\mathrm{CH}_{2}\right)_{11} \mathrm{NH}_{2}$ for $48 \mathrm{~h}$ to ensure wellordered amino ended self-assembled monolayers. After this treatment, the sensors were washed several times with ethanol, dried under $\mathrm{N}_{2}$ and placed in the QCM-D flow chambers. A stable baseline was acquired in $0.15 \mathrm{M} \mathrm{NaCl}$ solution at $25^{\circ} \mathrm{C}$. The polyelectrolytes $(0.5 \mathrm{mg} / \mathrm{mL})$ deposition was carried out at a constant flow rate ( $50 \mu \mathrm{L} / \mathrm{min})$. Each polyelectrolyte solution was injected into the measurement chamber for 10 min followed by a rinsing step with $0.15 \mathrm{M} \mathrm{NaCl}$ (pH 5.5) to remove loosely bound material. The measurements (changes in the frequency $\Delta \mathrm{F}$ and dissipation $\Delta \mathrm{D}$ ) were performed at several harmonics ( $n=3,5,7,9,11$ and 13$) . \Delta \mathrm{F} / n$ and $\Delta \mathrm{D}$ were fitted for the seventh and ninth overtone using the $\mathrm{Q}$-Tools software ( $v$ 3.0.6.213). Voigt element-based model was used to obtain the thickness of the produced multilayers.

\subsubsection{Characterization of multilayer coatings}

The multilayer coatings with 5 and 10 bilayers of $\mathrm{HA} / \mathrm{AC}_{\mathrm{sol}}$ and $\mathrm{HA} / \mathrm{AC}_{\mathrm{NSs}}$ were characterized by Attenuated Total Reflection Fourier Transform Infrared Spectroscopy (FTIR-ATR) using a Spectrum 100 FT-IR spectrometer (Perkin Elmer, USA). All FTIR-ATR spectra were obtained in the range of $4000-625 \mathrm{~cm}^{-1}$ performing 64 scans at $4 \mathrm{~cm}^{-1}$ resolution and the data analyzed using essential eFTIR 3.00.019 software. Prior to analysis, the coated silicone strips were thoroughly washed in distilled water at $100 \mathrm{rpm}$ for $24 \mathrm{~h}$ and then dried under $\mathrm{N}_{2}$ until no water was detected.

Morphology of the LbL coatings was investigated by scanning electron microscopy (SEM, JSM 5610, JEOL Ltd, Japan) and atomic force microscopy (AFM, Dimension 3100 AFM from Veeco Instruments, Inc USA). The AFM images were analyzed and processed using the Nanotec WSxM software [33].

Changes in the surface hydrophilicity of the material as a result of the polyelectrolyte deposition were followed by static water contact angle measurements (OCA 15+, DataPhysics Instruments, Germany) using the sessile drop method (drop of $1 \mu \mathrm{L}$ HPLC grade water). At least six measurements per sample were performed and averaged.

\subsubsection{Antimicrobial activity}

The antibacterial activity of the coated silicone toward the $P$. aeruginosa planktonic growth was evaluated using the shake flask method. Briefly, a single colony from the $P$. aeruginosa stock bacterial culture was grown overnight in nutrient broth (NB). Then, the bacterial cells were harvested by centrifugation and diluted in sterile $0.9 \%(\mathrm{w} / \mathrm{v})$ sodium chloride $(\mathrm{NaCl})$ solution, $\mathrm{pH} 6.5$, until reaching solution absorbance of $0.28 \pm 0.1$ at $600 \mathrm{~nm}$, which corresponds to $1.5-3.0 \times 10^{8} \mathrm{CFU} / \mathrm{mL}$. The silicone samples $(1 \times 1 \mathrm{~cm})$ were incubated with $2 \mathrm{~mL}$ cell suspension at $100 \mathrm{rpm}$ and $37^{\circ} \mathrm{C}$ for $2 \mathrm{~h}$. These suspensions were serially diluted in the same $\mathrm{NaCl}$ solution, then plated on a cetrimide agar and incubated at $37^{\circ} \mathrm{C}$ for $24 \mathrm{~h}$ to determine the number of viable bacteria. Three independent measurements were performed per sample and the results are expressed as a reduction percentage of the survived bacteria colonies (CFU) after incubation with the specimens (B) compared to the CFU survived from the suspension in contact with pristine silicone $(A)$, calculated as follows:

Reduction $(\%)=(\mathrm{A}-\mathrm{B}) / \mathrm{A} \times 100$

\subsubsection{Degradation of the coatings in presence of bacteria}

The degradation of the multilayer coatings in the presence of $P$. aeruginosa was assessed using fluorescein isothiocyanate (FITC)labeled AC component. Prior to immobilization, AC $(6 \mathrm{mg} / \mathrm{mL})$ was dissolved in $0.1 \mathrm{M}$ sodium carbonate buffer, $\mathrm{pH}$ 9. Then, $1 \mathrm{mg} / \mathrm{mL}$ FITC solution was prepared in anhydrous dimethyl sulfoxide (DMSO) and mixed with AC in buffer (for each $1 \mathrm{~mL}$ of $\mathrm{AC}$ $50 \mu \mathrm{L}$ of FITC was added). The reaction mixture was incubated in the dark at $4{ }^{\circ} \mathrm{C}$ for $12 \mathrm{~h}$. The unreacted FITC was separated from the AC-FITC conjugate using PD-10 Desalting Columns (GE healthcare). Then, the LbL assembly between HA and AC-FITC was performed on silicone strips as described above. The coated silicone samples were further cut in equal pieces and incubated in distilled $\mathrm{H}_{2} \mathrm{O}$ and growth medium (TSB) (both as control samples) and TSB containing $P$. aeruginosa $\left(\mathrm{OD}_{600}=0.01\right)$ at $37^{\circ} \mathrm{C}$ for 6 and $24 \mathrm{~h}$. At the end of these time intervals, the samples were withdrawn and washed with distilled $\mathrm{H}_{2} \mathrm{O}$ prior to analysis by fluorescence microscopy. The same microscope gain and offset settings were used to acquire all images. The stability of the coatings was further assessed by their fluorescence intensity in the absence and presence of $P$. aeruginosa.

\subsubsection{Biofilm inhibition test}

The ability of the coated materials to control pathogenic biofilm formation was studied using Live/Dead BacLight Bacterial viability kit. $P$. aeruginosa was grown overnight in optimized media conditions for biofilm growth. Then, coated and non-coated silicone samples were cut $(1 \times 1 \mathrm{~cm})$, placed in a 24 -well plate (Nunc) and inoculated with $1 \mathrm{~mL} P$. aeruginosa suspension diluted in tryptic soy broth (TSB) to $\mathrm{OD}_{600}=0.01$. After $24 \mathrm{~h}$ of incubation at $37^{\circ} \mathrm{C}$, the liquid broth was removed and the biofilms washed three times with sterile $0.9 \% \mathrm{NaCl}(\mathrm{pH} \mathrm{6.5)}$ to eliminate the non-adhered bacteria. Afterward, the live and dead bacteria in the biofilms were stained for 15 min with a mixture (1:1) of the fluorescent Syto 9 (green, live staining) and propidium iodide nucleic acid (red, dead staining) dyes. Then, the biofilm growth on the materials was observed using fluorescence microscopy at $\lambda_{\text {exc }} / \lambda_{\text {em }}=480 / 500 \mathrm{~nm}$ for Syto 9 and at $\lambda_{\text {exc }} / \lambda_{\text {em }}=490 / 635 \mathrm{~nm}$ for propidium iodide.

\subsubsection{Dynamic antibiofilm test}

Dynamic biofilm inhibition tests were performed in a physical glass model of catheterized bladder as previously described by Stickler et al. [34] and shown in Fig. S1. After sterilization of the model by autoclaving $\left(121^{\circ} \mathrm{C}\right.$ for $15 \mathrm{~min}$ ), a treated silicone Foley 
catheter was inserted into the system and the catheter balloon inflated with $5 \mathrm{~mL}$ sterile distilled $\mathrm{H}_{2} \mathrm{O}$. Then, the bladder was filled with $25 \mathrm{~mL}$ sterile artificial urine in accordance with UNE EN1616 (Sterile Urethral Catheters for Single Use), supplemented with $1 \mathrm{mg} \mathrm{mL}^{-1}$ TSB and inoculated with P. aeruginosa $\left(\mathrm{OD}_{600}=0.01\right)$. The catheterized bladder model was left for $1 \mathrm{~h}$ without urine supply to allow the organisms to adapt, and thereafter the supply was started with a $1 \mathrm{~mL} \mathrm{~min}^{-1}$ flow rate. After 7 days, the catheter was removed and thoroughly washed with distilled $\mathrm{H}_{2} \mathrm{O}$. The shaft and balloon of the catheter were subjected to analysis for biofilm formation using Live/Dead kit as described above. The same parts of untreated silicone Foley catheter were used as controls.

\subsubsection{Statistical analysis}

The results for the samples hydrophilicity and antibacterial activity are presented as mean value \pm standard deviation (SD). Statistical analysis was carried out by Graph Pad Prism 6 Software (USA) by performing a one way analysis of variance (ANOVA) followed by post hoc Tukey test to determine the statistical significance of the observed differences among the samples. The differences were considered significant only if $p<0.01$.

\section{Results}

\subsection{Assembling of the multilayer coatings}

The successful build-up of the LbL constructs was confirmed by QCM-D data suggesting an exponential growth of the coatings with each deposition (Fig. 1). Typical stepwise decrease in frequency $(\Delta \mathrm{F})$ was measured for both constructs, i.e. for $\left(\mathrm{HA} / \mathrm{AC}_{\mathrm{sol}}\right)_{5}$ and $\left(\mathrm{HA} / \mathrm{AC}_{\mathrm{NSs}}\right)_{5}$, showing the overall increased mass adsorption $(\Delta \mathrm{F}$ in Fig. 1, A1 vs. B1, black lines) bigger in the case of the coating obtained with $\mathrm{AC}_{\mathrm{sol}}$ as polycation. In contrast, more dissipative layers were measured for ( $\left.\mathrm{HA} / \mathrm{AC}_{\mathrm{NSs}}\right)_{5}$ (Fig. 1, A1 vs. B1, blue lines). The formation of the first layer, HA on APTES treated silicone is characterized with a strongly attached (very small $\Delta \mathrm{D}$ ) ad-layer formed (the first green arrows on Fig. 1, A1 and B1), followed by the attachment of a loosely bound polycation in both cases (Fig. 1, A3 and B3), seen via higher dissipation shifts from the second layers (the first red arrows on Fig. 1, A1 and B1). However, the absolute values for $\triangle D$, as well as the shape of the dissipation signal for the second layer are different for $\mathrm{AC}_{\mathrm{sol}}$ and $\mathrm{AC}_{\mathrm{NSs}}$. Upon the injection of $\mathrm{AC}_{\mathrm{sol}}$ in the $\mathrm{QCM}$ chamber, a burst increase of $\triangle \mathrm{D}$ is observed, followed by a common stabilization of the dissipation signal (marked by the first blue arrow on Fig. 1, A1). When $\mathrm{AC}_{\mathrm{NSs}}$ is used as a polycation, a steady increase of $\triangle D$ is detected instead. We have also plotted $\Delta \mathrm{D}$ vs. $\Delta \mathrm{F}$ (Fig. $1, \mathrm{~A} 2$ and $\mathrm{B} 2$ ) to relate the dissipation caused by a unit frequency (mass) change. A comparison between these two plots demonstrate clearly that in the case of $\left(\mathrm{HA} / \mathrm{AC}_{\mathrm{NSs}}\right)_{5}$ there is less adsorbed material that is more dissipative in comparison with the $\left(\mathrm{HA} / \mathrm{AC}_{\mathrm{Sol}}\right)_{5}$. Finally, the thicknesses of the constructs were calculated by a viscoelastic model based on a Voigt element. We obtained $82.33 \mathrm{~nm}$ for the $\left(\mathrm{HA} / \mathrm{AC}_{\mathrm{sol}}\right)_{5}$ and $141.5 \mathrm{~nm}$ for the $\left(\mathrm{HA} / \mathrm{AC}_{\mathrm{NSs}}\right)_{5}$ constructs.

\subsection{Characterization of the coated silicone materials}

FTIR-ATR confirmed the presence of the multilayer assemblies on the surface of silicone (Fig. 2). Three new bands appeared in spectra of all coated strips: the signal at around $3300 \mathrm{~cm}^{-1}$ was assigned to stretching vibrations of $\mathrm{N}-\mathrm{H}$ and $\mathrm{O}-\mathrm{H}$ in $\mathrm{AC}$, and $\mathrm{O}-\mathrm{H}$ in $\mathrm{HA}$, whereas the broad band between $1500 \mathrm{~cm}^{-1}$ and $1700 \mathrm{~cm}^{-1}$ was associated with the amines of AC. In general, all the bands were more pronounced after the deposition of 10 bilayers revealing that the coating thickness is directly proportional to the number of the deposited layers. Moreover, several new peaks appeared in the spectra of $\mathrm{HA} / \mathrm{AC}_{\mathrm{NSs}}$ specimens (containing sunflower oil), particularly pronounced in $\left(\mathrm{HA} / \mathrm{AC}_{\mathrm{NSs}}\right)_{10}$ spectra (marked with arrows). The peaks at around $2930 \mathrm{~cm}^{-1}$ and $2850 \mathrm{~cm}^{-1}$ could be associated to $\mathrm{C}-\mathrm{H}$ stretching vibrations in methylene $\left(-\mathrm{CH}_{2}-\right)$ and methyl groups $\left(-\mathrm{CH}_{3}\right)$, respectively, whereas the large peak around $1740 \mathrm{~cm}^{-1}$ is due to $\mathrm{C}=0$ double bond stretching vibration.

The coating deposition was also suggested by changes in the wettability of the treated silicone (Fig. S2). The untreated silicone is a hydrophobic surface $\left(112.7 \pm 0.4^{\circ}\right)$. Upon coating, the water contact angle decreased significantly $(p<0.01)$ only for $\left(\mathrm{HA} / \mathrm{AC}_{\mathrm{sol}}\right)_{10}\left(83.4 \pm 1.7^{\circ}\right)$, whereas the values measured for the silicone functionalized with $\left(\mathrm{HA} / \mathrm{AC}_{\mathrm{sol}}\right)_{5}, \quad\left(\mathrm{HA} / \mathrm{AC}_{\mathrm{NSs}}\right)_{5}$ and $\left(\mathrm{HA} / \mathrm{AC}_{\mathrm{NSs}}\right)_{10}$ were $105.9 \pm 0.6^{\circ}, \quad 111.0 \pm 0.5^{\circ}$ and $106.4 \pm 2.6^{\circ}$ respectively (Fig. 2, inset images).

The surface topography and morphology of the 10-bilayered coatings were visualized using AFM and SEM. Both $\left(\mathrm{HA} / \mathrm{AC}_{\mathrm{sol}}\right)_{10}$ and $\left(\mathrm{HA} / \mathrm{AC}_{\mathrm{NSs}}\right)_{10}$ coatings exhibited rough and irregular surfaces (Fig. $3 \mathrm{~A}$ ). The mean squared roughness (R) values were $7.7 \mathrm{~nm}$ and $3.0 \mathrm{~nm}$, whereas the average heights $(\mathrm{H})$ were $2.6 \mathrm{~nm}$ and $1 \mathrm{~nm}$ for $\mathrm{AC}_{\mathrm{sol}}$ and $\mathrm{AC}_{\mathrm{NSs}}$ coatings respectively. Unexpectedly, the profile of the $A_{\mathrm{NSs}}$ coating was smoother compared to the one built with $\mathrm{AC}_{\text {sol. }}$.

SEM images taken at the cross-section of the coatings confirmed an irregular surface structure after 10 depositions, but also revealed a complete surface coverage by either $\left(\mathrm{HA} / \mathrm{AC}_{\mathrm{sol}}\right)_{10}$ or $\left(\mathrm{HA} / \mathrm{AC}_{\mathrm{NSs}}\right)_{10}$ (Fig. 3B). The dry thicknesses of $\sim 3 \mu \mathrm{m}$ for $\left(\mathrm{HA} / \mathrm{AC}_{\mathrm{sol}}\right)_{10}$ and $\sim 7 \mu \mathrm{m}$ for $\left(\mathrm{HA} / \mathrm{AC}_{\mathrm{NSs}}\right)_{10}$ confirmed the same tendency as calculated from the $\mathrm{QCM}-\mathrm{D}$ data $-\mathrm{AC}_{\mathrm{NSs}}$ coating is thicker. Since the outermost layer of the coatings was made from the polycations, the top view on the surface revealed additional details about the coating structures (Fig. $3 \mathrm{C}$ ). The key difference was the presence of nanospheres on top of $\left(\mathrm{HA} / \mathrm{AC}_{\mathrm{NSs}}\right)_{10}$, which appear intact (black arrows in Fig. 3C).

\subsection{Antimicrobial action upon bacteria-induced degradation of coatings}

A significant improvement $(p<0.001)$ in inhibition of the $P$. aeruginosa growth was observed already after a $2 \mathrm{~h}$ incubation with most of the specimens, compared to the control (noncoated silicone). The $\mathrm{AC}_{\mathrm{NSs}}$ in the multilayer coatings (5 and 10 sequential depositions) reduced planktonic bacterial growth similarly (around $70 \%$ ), whereas the $\mathrm{AC}_{\text {sol }}$-based coatings affected up to $42 \%$ the bacterial cells (Fig. 4, Table S1). Interestingly, in the case of $\left(\mathrm{HA} / \mathrm{AC}_{\mathrm{sol}}\right)$, the 5-bilayer coating was more efficient compared to the 10-bilayer one, which reduced the bacterial growth by only $9 \%$.

On the other hand, the incubation of $\left(\mathrm{HA} / \mathrm{AC}_{\mathrm{NSs}}\right)_{10}$ multilayer in $P$. aeruginosa suspension resulted in a partial collapse of the coating (Fig. 5). After a $6 \mathrm{~h}$ incubation the coating was still completely covering the silicone surface, although lower fluorescence indicates loss of upper layers of the structure. Further incubation with the bacteria resulted in merely a partial silicone coverage. But even after $24 \mathrm{~h}$ the coating was found on the surface, revealing a gradual disintegration of the structure in bacterial presence. The degradation was in contrast to the coating stability in water and the culture broth.

\subsection{Antibiofilm properties}

\subsubsection{Static conditions}

The potential of $\mathrm{HA} / \mathrm{AC}_{\mathrm{NSs}}$ and $\mathrm{HA} / \mathrm{AC}_{\text {sol }}$ coated silicones to prevent $P$. aeruginosa biofilm formation in static conditions was investigated using fluorescence microscopy. Microscopy images after staining of live (green) and dead (red) bacteria attached to 

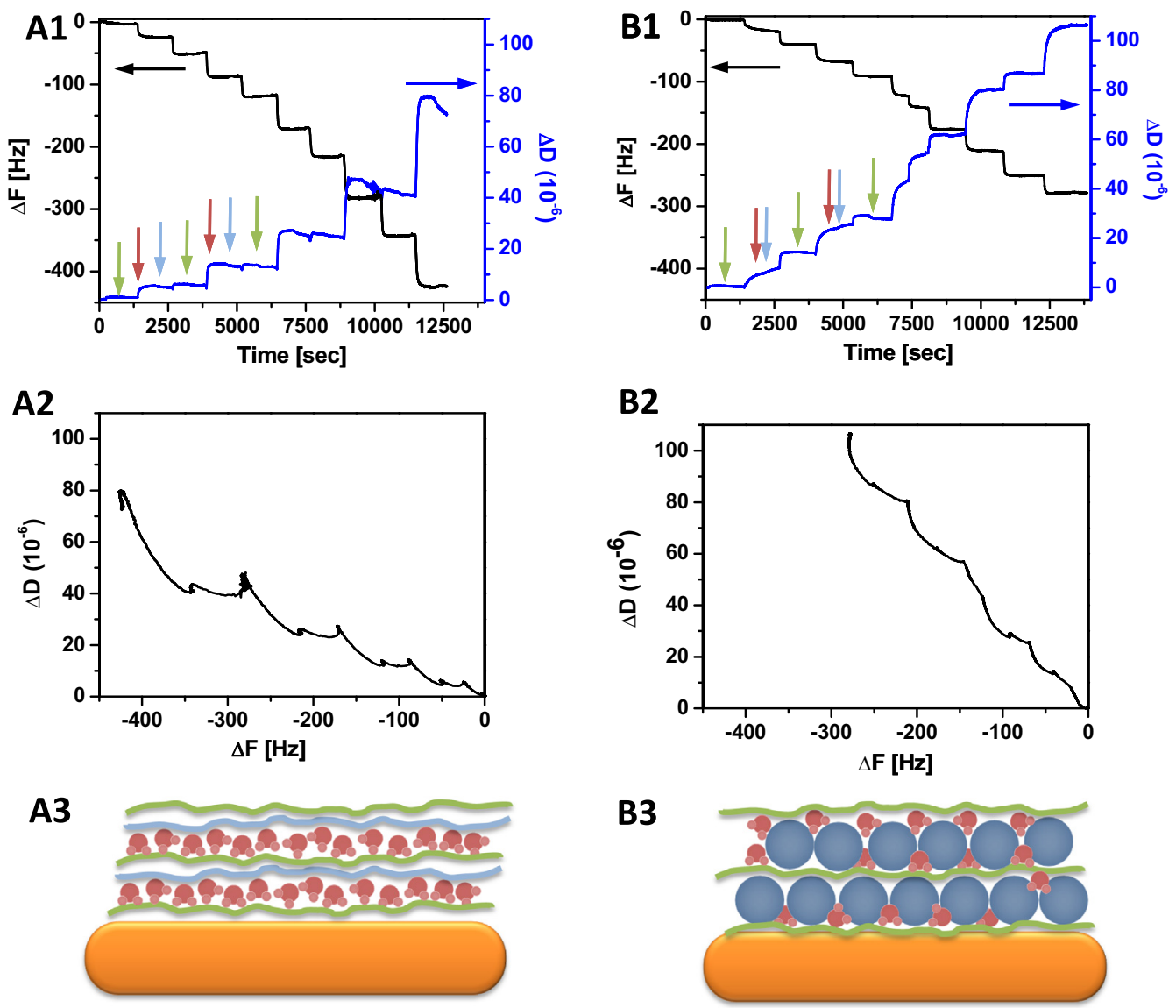

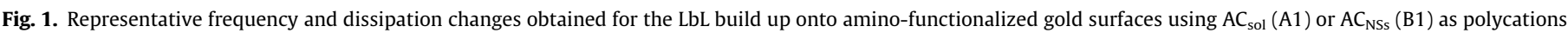

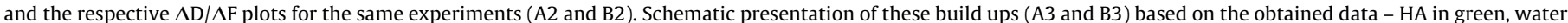

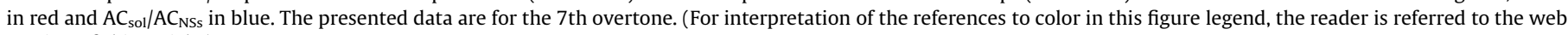
version of this article.)

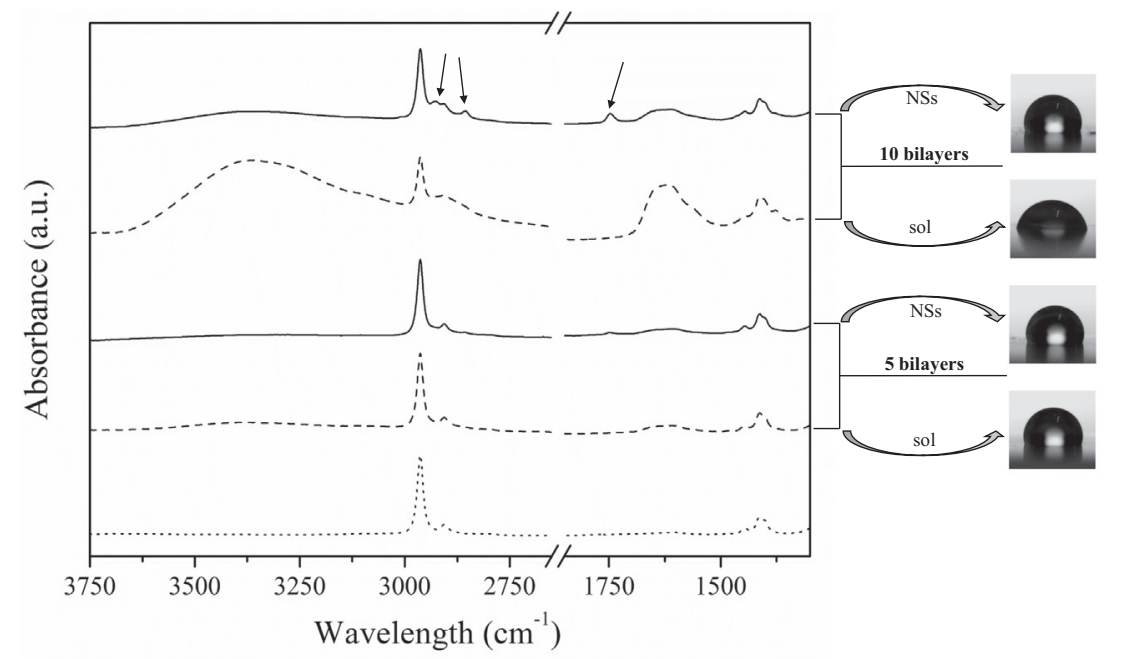

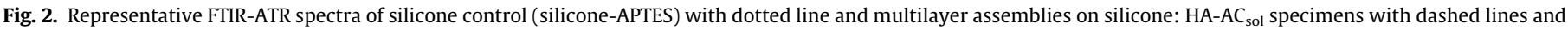
$\mathrm{HA}-\mathrm{AC}_{\mathrm{NSs}}$ specimens with full lines. Images of water contact angle measurements are given on the side for each specimen.

the surface showed that the bacteria develop well-established biofilms on the control material (non-treated silicone), with several colonies merging into a continuous biofilm (Fig. 6). The surfaces with deposited 5 bi-layers were still colonized with bacteria, although the biofilm occurrence was considerably lower and represented with a smaller number of bacterial clusters. Despite the decrease in total biofilm growth for both $\mathrm{AC}_{\mathrm{NSs}}{ }^{-}$and $\mathrm{AC}_{\mathrm{sol}}$-based coatings, better antibiofilm effect was observed for the $A_{\mathrm{NSs}}$ coatings. The $P$. aeruginosa cells were individually spread on the latter assemblies with limited number of aggregates that consisted mainly of dead cells (stained in red). After assembling 10 bilayers the differences in the biofilm inhibition properties between the 
A
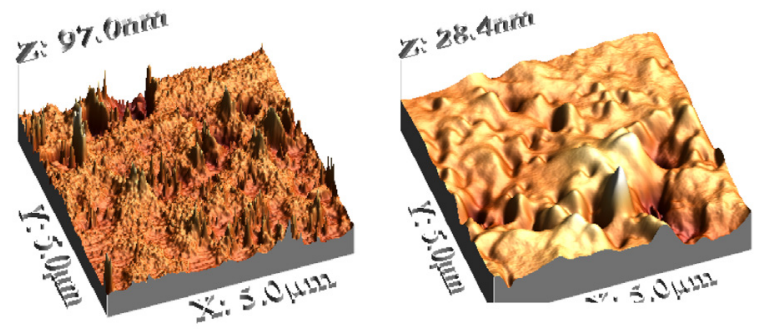

B
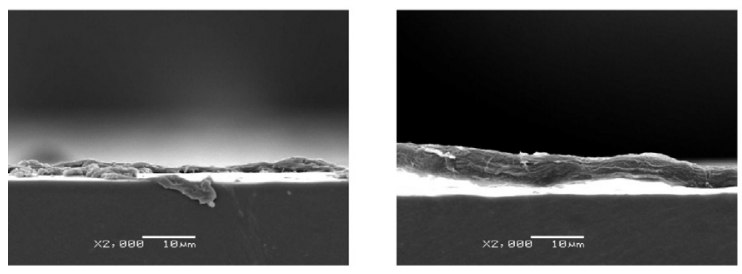

C
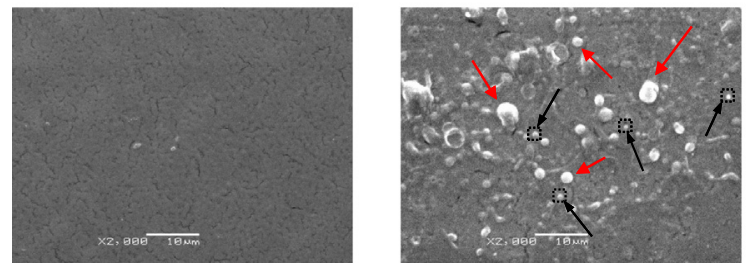

Fig. 3. (A) AFM images $\left(5 \times 5 \mu \mathrm{m}^{2}\right)$ of $\left(\mathrm{HA} / \mathrm{AC}_{\mathrm{sol}}\right)_{10}$ and $\left(\mathrm{HA} / \mathrm{AC}_{\mathrm{NSs}}\right)_{10}$ deposited onto silicone strips. (B) Cross-section and (C) top view of the same samples taken with SEM.

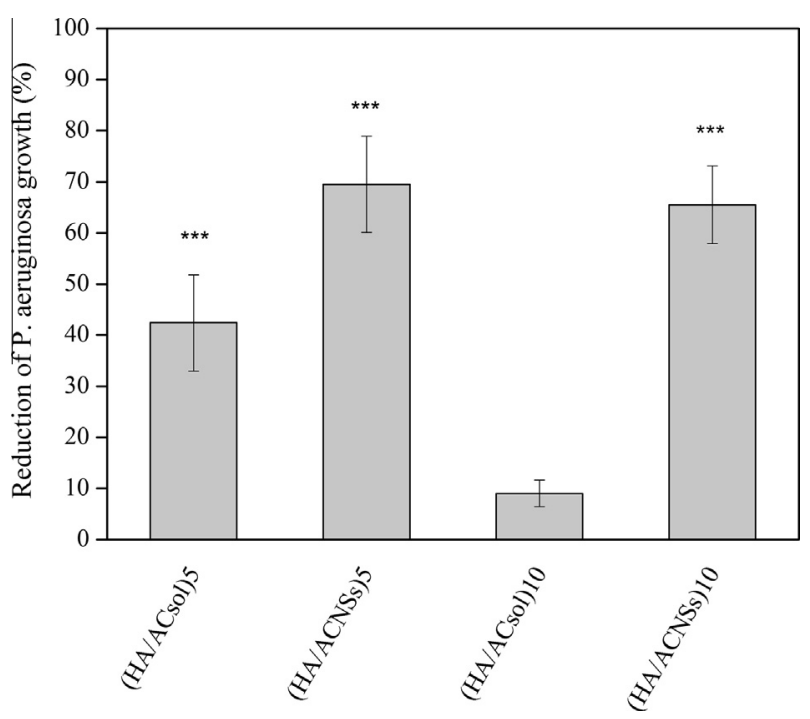

Fig. 4. Antibacterial activity of silicone coated with $\mathrm{HA} / \mathrm{AC}_{\mathrm{sol}}$ and $\mathrm{HA} / \mathrm{AC}_{\mathrm{NSs}}$ against $P$. aeruginosa as compared to pristine silicone. Statistical differences are represented as ${ }^{* * *} p<0.001$.

two specimens were not that obvious: both 10 bilayer coatings showed higher biofilm inhibition efficiency compared to the 5 bilayer structures. Only few live bacteria were detected on (HA/ $\left.\mathrm{AC}_{\mathrm{sol}}\right)_{10}$ coating, whereas the sporadic single cells on $\mathrm{AC}_{\mathrm{NSs}}$-based surface were all dead.

\subsubsection{Dynamic conditions - catheterized bladder model}

The biofilm inhibition capacity of urinary catheter coated with $\left(\mathrm{HA} / \mathrm{AC}_{\mathrm{NSs}}\right)_{10}$ was also assessed under dynamic conditions in an in vitro model of catheterized bladder (Fig. S1). Prior to the assay, photos were taken of an untreated Foley catheter and the LbLtreated one. A clean surface is seen on the untreated catheter, whereas the immobilization of $\mathrm{AC}_{\mathrm{NSs}}$ could be appreciated by a white color on the catheter surface, typical for materials comprising this type of nanospheres (left side photo in Fig. 7). Upon analysis, after 7 days in the catheterized bladder model, a bacterial biofilm is formed on the pristine catheter (especially visible on the catheter shaft), whereas the LbL-treated one was biofilm-free (photos in the middle in Fig. 7). Fluorescence images after staining of live and dead bacteria attached to the inner part of the catheter shaft confirmed the biofilm formation on the non-treated catheter and the absence of biofilm on the LbL-treated catheter (right side photos in Fig. 7). Unfortunately, the coatings were not as effective in inhibiting biofilm formation in the balloon section, although the effect is visible to a certain extent (Fig. S4).

\section{Discussion}

The rationale of this work comes from our previous findings that planktonic bacteria are more susceptible to membrane disruption by polycations processed in the form of nanospheres than the polycations in solution [27]. The efficient disruption of bacterial membrane and consequent bactericidal activity are the result of massive membrane surface defects caused by the nanospheres, compared to the limited effect of the free macromolecules to extend the already existing defects. In addition, the use of sonochemical technology for generation of nanostructures is justified by its simplicity (one-step), fastness ( $3 \mathrm{~min}$ ) and absence of aggressive organic solvents. The sonochemical approach consists in emulsification of aqueous solutions of polymers and a lipid component to obtain a two-phase mixture, shaping the polymers around the lipid nano-droplets and stabilizing the polymer shell/oil core systems. As previously reported [27], $\mathrm{AC}_{\mathrm{NSs}}$ form stable dispersion with spheres of an average hydrodynamic diameter of $268 \pm 7 \mathrm{~nm}$, polydispersity index of $0.047 \pm 0.009$, and extremely high $\zeta$-potential of $+103 \pm 2 \mathrm{mV}$. This study further exploits the possibility for coating of indwelling medical devices with intact polycationic nanospheres in order to engineer novel antimicrobial surfaces. Thus, LbL coatings containing $\mathrm{AC}_{\mathrm{NSs}}$ were built on silicone urinary catheters and their antimicrobial effectiveness was further evaluated.

Regarding the assembly of the HA/AC multilayer coatings, since $\Delta \mathrm{F}$ accounts for both polyion and water deposition on the QCM crystal, the bigger mass adsorption obtained for $\mathrm{AC}_{\mathrm{sol}}$ specimen may indicate less adsorbed polycation in the case of $A_{\text {NSs }}$ or more hydrated LbL constructs when $\mathrm{AC}_{\text {sol }}$ is used. The dissipation curves supported the former statement as true. The formation of the first layer is the same for both constructs and it is merely electrostatically driven, as the negatively charged carboxyl groups from HA interact with the positively charged amino groups (from APTES) available on the silicone surface. Because of the charge compensation between the surface and the first layer, the second layer is not fixed by strong electrostatic interactions. Weakly bound polycations (from the second layer) allow for a larger amount of trapped water that contributes to the higher dissipation shifts [35]. The shape of the shifts for the second layer are different for $\mathrm{AC}_{\mathrm{sol}}$ and $\mathrm{AC}_{\mathrm{NSs}}$, because of the different structure of the employed polycations: $\mathrm{AC}_{\text {sol }}$ is a linear polymer deposited in a single step, while $\mathrm{AC}_{\mathrm{NSs}}$ has a spherical shape that needs reorganization and hydration upon deposition. The greater dissipation measured for $\mathrm{AC}_{\mathrm{NS}}$ can be related with both the shape of the nanospheres and the hydration state of the layers. Moreover, the difference in the adsorbed material reflected in the $\Delta \mathrm{D} / \Delta \mathrm{F}$ plot is expected, since $\mathrm{AC}_{\mathrm{NSs}}$ cannot be closely packed in a layer because of the repulsion 
$\mathrm{H}_{2} \mathrm{O}$

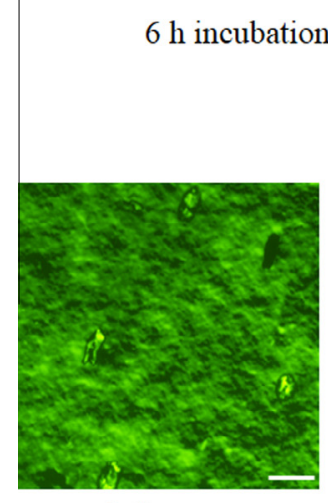

0 time

$24 \mathrm{~h}$ incubation
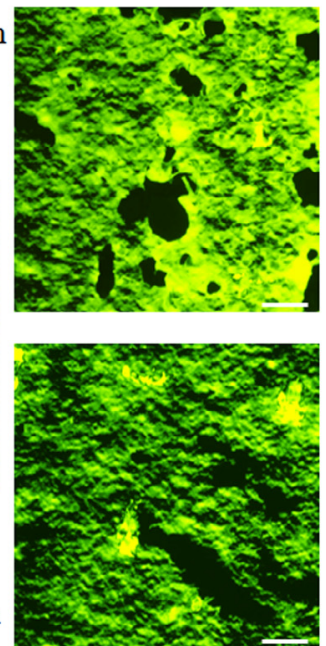

TSB
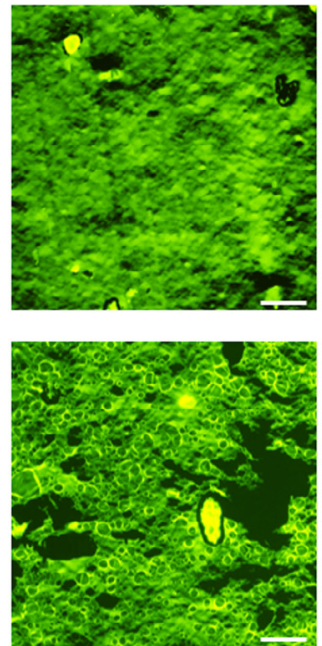

TSB with $P$. aeruginosa
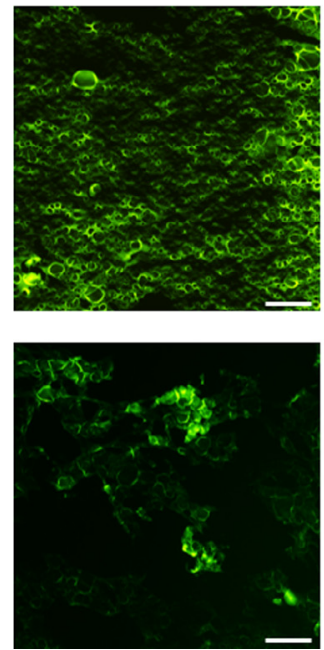

Fig. 5. Fluorescence microscopy $\left(20 \times\right.$ magnification) of $\left(\mathrm{HA} / \mathrm{AC}_{\mathrm{NSs}}\right)_{10}$ coating incubated for 6 and $24 \mathrm{~h}$ in the absence and presence of $P$. aeruginosa. Scale bars $100 \mu \mathrm{m}$.

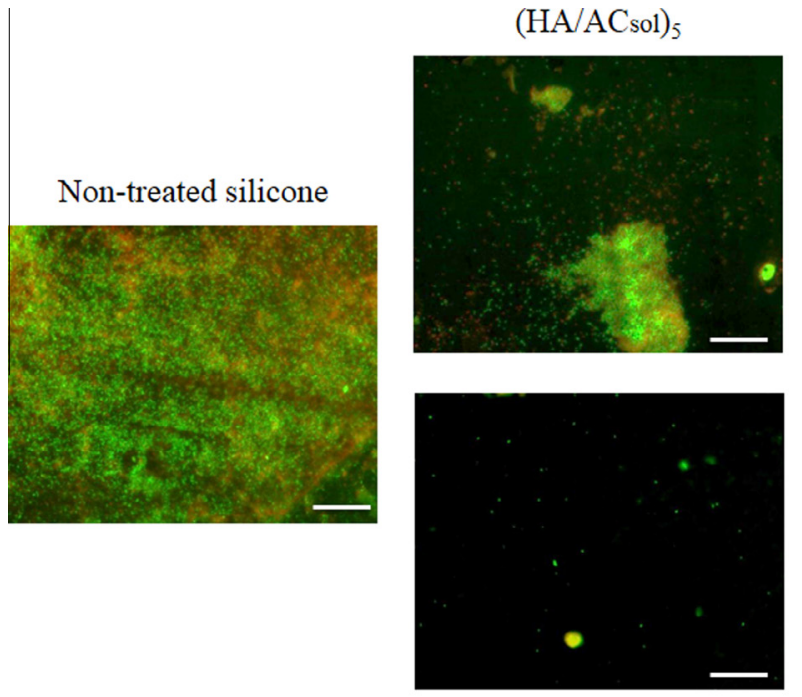

$(\mathrm{HA} / \mathrm{AC}$ sol $) 10$
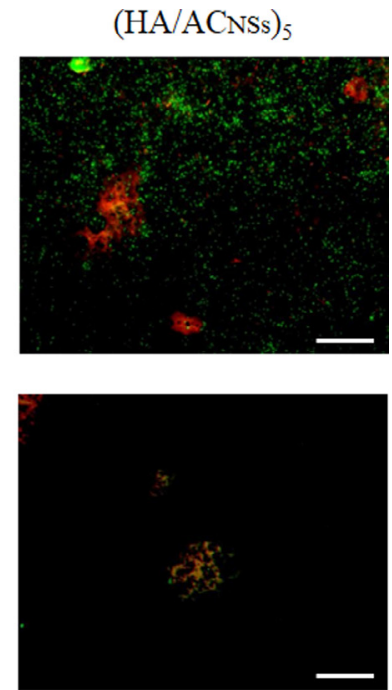

$(\mathrm{HA} / \mathrm{ACNSs})_{10}$

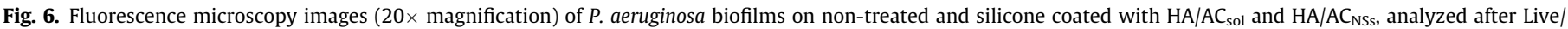
Dead staining. Scale bars $100 \mu \mathrm{m}$.

forces between the nanospheres due to their high positive charge (the main reason for the stability of $\mathrm{AC}_{\mathrm{NSs}}$ dispersion). The free space between the spheres is hydrated and as a result the obtained layer is much more dissipative. The differences in the structure of the used polycations and the mechanism of their deposition were also reflected in the thickness of the final constructs. The main observation from QCM-D findings is that the thickness is not fully a function of the adsorbed material, but also depends on the structure and shape of the used polyions.

The typical AC and HA bands found in FTIR-ATR spectra of the coatings were more intense when $A_{\text {sol }}$ was used for multilayer build-up (dotted lines), again suggesting more deposited material when compared to $\mathrm{HA} / \mathrm{AC}_{\mathrm{NSs}}$ coatings. Other peaks that appeared in the spectra of $\left(\mathrm{HA} / \mathrm{AC}_{\mathrm{NSs}}\right)_{5}$ and $\left(\mathrm{HA} / \mathrm{AC}_{\mathrm{NSs}}\right)_{10}$ could be associated with triglycerides [36] and fatty acids [37] due to the presence of the residual sunflower oil in the samples.

The contact angle measurements demonstrated that 5 sequential depositions are not sufficient to alter significantly the silicone wettability, regardless of the used AC. On the other hand, despite the lower degree of polyion deposition, the higher hydrophobicity of both $\mathrm{HA} / \mathrm{AC}_{\mathrm{NSs}}$ specimens is explained by the presence of oil in the nanospheres core which additionally repels water from the silicone surface.

Irregular surfaces of the coatings seen on AFM images were represented as typical for LbL structures submicrometer-sized outer islets of the material distributed over the surface [38]. Increased roughness of the $\mathrm{AC}_{\text {sol-containing compared to relatively smooth }}$ surface of the structure with nanospheres is owed to the higher mobility of the free biopolymer, which after deposition takes the shape of the previous layer. Taking into account that the buildup of multilayer constructs starts with the formation of isolated islets that grow and coalesce into continuous coatings only in the second stage of the build-up process [39] (usually above 10 bilayers), the obtained AFM profile for $\left(\mathrm{HA} / \mathrm{AC}_{\mathrm{sol}}\right)_{10}$ is expected. In contrast, $\mathrm{AC}_{\mathrm{NSs}}$ solely dictates the morphology of the multilayer constructs independently of the shape below the layers. Due to 
Before dynamic assay

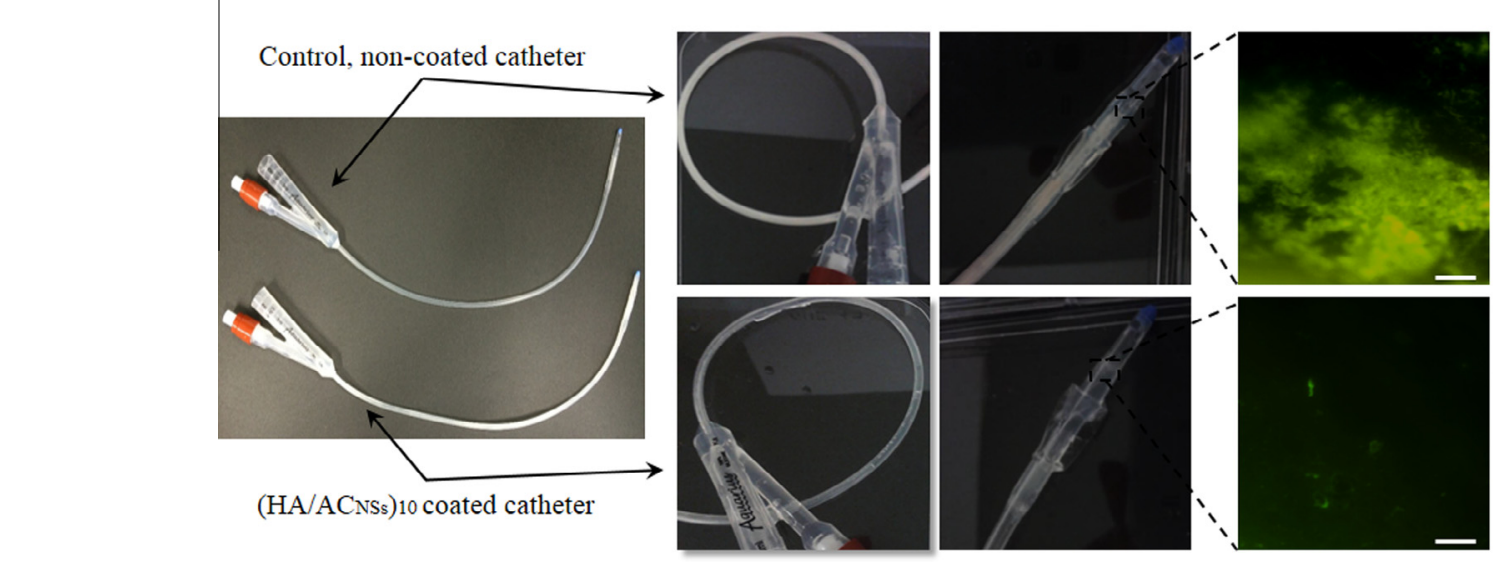

After 7 days in bladder model with Pseudomonas aeruginosa
Live/Dead kit evaluated in catheter shaft

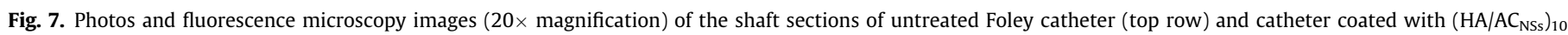
(bottom row) after a 7 day incubation in a dynamic bladder model system with P. aeruginosa. Scale bars $100 \mu \mathrm{m}$.

both spherical shape and lower mobility of the nanospheres the related coating displayed a smoother surface [18].

Important for proving the hypothesis that nanostructures are more efficient that their molecular counterparts even after immobilization onto solid surfaces, the incorporation of the intact soft nanospheres in our multilayer structures (seen in SEM images in Fig. 3) made further investigation relevant. Besides the nanospheres, some bigger than $1 \mu \mathrm{m}$ formations (marked with red arrows on Fig. 3C), also visible are oil bubbles which were not removed by the centrifugation steps. Previously we have observed the same artefacts in $\mathrm{AC}_{\mathrm{NSs}}$ dispersions [27]. This finding was also confirmed by the presence of the residual sunflower oil, identified with FTIR. Overall, the assembling of multilayers using intact core/ shell nanospheres with a soft core as in our case, is considered advantageous, since the added value of processing polymers into nanostructures could be transferred to the functionalized materials/surfaces.

Antibacterial and antibiofilm activities of the developed coatings were assessed against $P$. aeruginosa, which is among the most common Gram-negative bacteria involved in biofilm-associated infections [40]. AC is a well known antibacterial agent owing to its positive charge and related perturbation of the bacterial membrane [41]. AC processed into nanospheres displays even higher disturbing capacity on the bacterial membrane and bactericidal effect on planktonic bacteria [27]. Such a bactericidal mechanism induces less selective pressure on the bacterial population and consequently reduces the risk of resistance development. After proving their effectiveness in solution, the next step is incorporation of these antibacterial nanospheres into biomedical devices to effectively control nosocomial infections. In this aspect, building the multilayer polyelectrolyte coatings is regarded as a simple, but efficient approach for immobilization of bioentities with preserved bioactivity [42].

After assembling the polycationic $\mathrm{AC}_{\mathrm{NSs}}$ on silicone surfaces in a LbL fashion we further demonstrated an improvement of the $P$. aeruginosa growth inhibition in comparison to the multilayers comprising $\mathrm{AC}_{\mathrm{sol}}$ counterparts. Also, due to an unexpected finding that $\mathrm{AC}_{\mathrm{sol}}$ was more efficient in the coating with less bilayers we relate to the motility of the layers and their availability to interact with bacterial cells. An increased motility of the layers in thicker coatings usually favors bioactivity, e.g. antimicrobial effect, due to improved availability of polycations [31]. Nevertheless, the deposition of a greater number of layers also results in enhanced motility of a polycation which could lower the effect. A lower hydration of the thinner assemblies results in compactly packed structures (reduced mobility) that favor the interactions between the polycation and adhered bacterial cells, which could result in a stronger effect. In this study, the $\left(\mathrm{HA} / \mathrm{AC}_{\mathrm{sol}}\right)_{10}$ coating was more hydrated with higher motility of the polyelectrolytes, which translates into less amino groups of AC available on the surface to interact with bacteria membranes, and consequently a lower antibacterial activity. Nevertheless, such a phenomenon was not observed for the $\mathrm{AC}_{\mathrm{NSs}}$ coatings where the nanospheres preserve the polymer motility regardless of the number of deposited layers. In this case the effect may be also assigned to the large surface area and improved cationic character of $\mathrm{AC}_{\mathrm{NSs}}$ when compared to $\mathrm{AC}_{\mathrm{sol}}$.

The integrity of the multilayer coatings after contact with $P$. aeruginosa was evaluated in order to elucidate whether the antibacterial effect of the nanospheres was due to their release or they act from the surface. The coating degradation by $P$. aeruginosa could be explained by the expressed hydrolytic activity and depolymerization of the HA component. In such a scenario, the antibacterial effect is a consequence of the release of the antibacterial $\mathrm{AC}_{\mathrm{sol}}$ and $\mathrm{AC}_{\mathrm{NSs}}$ upon triggering by the bacteria degradation of the coating. Thus, the effective bacteria killing by $\left(\mathrm{HA} / \mathrm{AC}_{\mathrm{sol}}\right)_{10}$ and especially ( $\left.\mathrm{HA} / \mathrm{AC}_{\mathrm{NSs}}\right)_{10}$ coatings can be attributed to the locally high concentrations of polycationic antibacterials released. Release from the catheter coatings into a narrow space is relevant for urinary tract infections, where typically a small volume of urine surrounds the indwelling device surface. Even more important, a gradual collapse detected together with only a partial loss of the coating indicated a possible achieving of a day-long effect.

Regarding biofilm studies, $P$. aeruginosa biofilm is typically developed from the mushroom-like biofilm colonies that grow/ encase in a two-stage process [43]. The growth of a continuous film made of such colonies could be effectively prevented by the herein suggested multilayer coatings, especially those incorporating intact AC nanospheres, due to their stronger antibacterial effect. Increasing number of layers brought about nearly total prevention of the biofilm formation, regardless of the shape of the AC polycation (free polymer vs. nanospheres). Nevertheless, it should be taken into account in this comparison that less material is deposited in the case of $\mathrm{AC}_{\mathrm{NSs}}$ (based on QCM-D and FTIR data), confirming that the embedded nanospheres also have stronger antibiofilm activity than the free AC macromolecules (deposited from solution). Interestingly, despite the negligible antibacterial effect observed for $\mathrm{AC}_{\text {sol }}$ assemblies with 10 bilayers (less than $10 \%$, Fig. 4), these coatings still effectively prevented the biofilm growth. 
Such observation could be explained with their relatively high hydrophilicity compared to the other multilayers (Fig. 2). Hydrophobic interactions are suggested as one of the important factors promoting $P$. aeruginosa attachment and consequent biofilm development on silicone surfaces. This pathogen possesses a thin layer of glycoprotein covered by a thicker layer of lipoproteins and lipids that facilitate its interaction with hydrophobic surfaces such as silicone [44]. Thus, increased surface hydrophilicity is another way to prevent biofilm formation without affecting planktonic bacterial growth, as in the case of the $\left(\mathrm{HA} / \mathrm{AC}_{\mathrm{sol}}\right)_{10}$ coating.

Our investigation in the catheterized bladder model also suggested that the $\mathrm{AC}_{\mathrm{NSs}}$-containing coating is effective in biofilm prevention on the commercially available Foley catheter, acting upon its degradation by $P$. aeruginosa and the consequent nanosphere release (the catheter displayed a clean surface after the incubation in the bladder model). The results obtained with the dynamic system showed thus the same tendency in inhibiting biofilm formation as in static conditions. These findings represent a proof-of-concept for antimicrobial effectiveness of the novel nanosphere-containing coatings evaluated during 7 days - a period longer than the useful lifetime of clinically employed urinary catheters. Nevertheless, the stability, possible degradation and antibiofilm performance of the coatings over the time of use should be further considered for in vivo and evidence-based studies.

\section{Conclusions}

In this study, cationic nanostructures were employed as powerful bactericides with great potential in suppressing biofilms because of the minimum risk of bacteria resistance development. These were incorporated into catheter surface coatings in order to elicit their effect only in the presence of pathogenic bacteria, e.g. upon release triggered by a certain stimuli, aiming to avoid unnecessary elution and rendering the coating inefficient. We demonstrated that the layer-by-layer deposition of hyaluronic acid and aminocellulose nanospheres resulted in inclusion of intact nanospheres within the bacteria-responsive coating, as a key for effective prevention of bacterial biofilms. The coatings were noneluting in physiological conditions, but gradually degraded in the presence of $P$. aeruginosa that causes most of the infections related to biofilm formation on urinary catheters. The responsiveness of the constructs due to the presence of bacteria leads to eradication of the biofilm upon release of the aminocellulose nanospheres. The antibiofilm properties were also demonstrated in a catheterized bladder model during seven days - far beyond the useful lifetime of urinary catheters.

\section{Acknowledgements}

M.M.F. acknowledges the support of the European Commissionunder the Marie Curie Intra-European Fellowship (IEF) Program (Grant Agreement "NanoQuench" FP7-331416).

\section{Appendix A. Supplementary data}

Supplementary data associated with this article can be found, in the online version, at http://dx.doi.org/10.1016/j.actbio.2016.01. 020 .

\section{References}

[1] N. Høiby, T. Bjarnsholt, M. Givskov, S. Molin, O. Ciofu, Antibiotic resistance of bacterial biofilms, Int. J. Antimicrob. Agents 35 (2010) 322-332.

[2] J.W. Warren, Catheter-associated urinary tract infections, Int. J. Antimicrob. Agents 17 (2001) 299-303.
[3] Y. Dong, X. Li, T. Bell, R. Sammons, H. Dong, Surface microstructure and antibacterial property of an active-screen plasma alloyed austenitic stainless steel surface with Cu and N, Biomed. Mater. 5 (2010) 054105.

[4] E. Fadeeva, V.K. Truong, M. Stiesch, B.N. Chichkov, R.J. Crawford, J. Wang, E.P. Ivanova, Bacterial retention on superhydrophobic titanium surfaces fabricated by femtosecond laser ablation, Langmuir 27 (2011) 3012-3019.

[5] N.J. Hickok, I.M. Shapiro, Immobilized antibiotics to prevent orthopaedic implant infections, Adv. Drug Delivery Rev. 64 (2012) 1165-1176.

[6] X. Wang, S.S. Venkatraman, F.Y.C. Boey, J.S.C. Loo, L.P. Tan, Controlled release of sirolimus from a multilayered PLGA stent matrix, Biomaterials 27 (2006) 5588-5595.

[7] Q. Xu, J.T. Czernuszka, Controlled release of amoxicillin from hydroxyapatitecoated poly(lactic-co-glycolic acid) microspheres, J. Control. Release 127 (2008) 146-153.

[8] T. Crouzier, T. Boudou, C. Picart, Polysaccharide-based polyelectrolyte multilayers, Curr. Opin. Colloid Interface Sci. 15 (2010) 417-426.

[9] D.T. Haynie, L. Zhang, J.S. Rudra, W. Zhao, Y. Zhong, N. Palath, Polypeptide multilayer films, Biomacromolecules 6 (2005) 2895-2913.

[10] F. Caruso, C. Schüler, Enzyme multilayers on colloid particles: assembly, stability, and enzymatic activity, Langmuir 16 (2000) 9595-9603.

[11] M.C. Berg, L. Zhai, R.E. Cohen, M.F. Rubner, Controlled drug release from porous polyelectrolyte multilayers, Biomacromolecules 7 (2006) 357-364.

[12] M. Kolasinska, T. Gutberlet, R. Krastev, Ordering of $\mathrm{Fe}_{3} \mathrm{O}_{4}$ nanoparticles in polyelectrolyte multilayer films, Langmuir 25 (2009) 10292-10297.

[13] K. Ivanova, M. Fernandes, E. Mendoza, T. Tzanov, Enzyme multilayer coatings inhibit Pseudomonas aeruginosa biofilm formation on urinary catheters, Appl. Microbiol. Biotechnol. 99 (2015) 4373-4385.

[14] S. Pavlukhina, Y. Lu, A. Patimetha, M. Libera, S. Sukhishvili, Polymer multilayers with pH-triggered release of antibacterial agents, Biomacromolecules 11 (2010) 3448-3456.

[15] D.J. Schmidt, J.S. Moskowitz, P.T. Hammond, Electrically triggered release of a small molecule drug from a polyelectrolyte multilayer coating, Chem. Mater. 22 (2010) 6416-6425.

[16] Z. Zhu, N. Gao, H. Wang, S.A. Sukhishvili, Temperature-triggered on-demand drug release enabled by hydrogen-bonded multilayers of block copolymer micelles, J. Control. Release 171 (2013) 73-80.

[17] V.V. Komnatnyy, W.C. Chiang, T. Tolker-Nielsen, M. Givskov, T.E. Nielsen, Bacteria-triggered release of antimicrobial agents, Angew. Chem. Int. Ed. 53 (2014) 439-441.

[18] I. Zhuk, F. Jariwala, A.B. Attygalle, Y. Wu, M.R. Libera, S.A. Sukhishvili, Selfdefensive layer-by-layer films with bacteria-triggered antibiotic release, ACS Nano 8 (2014) 7733-7745.

[19] A.B.H. Khalifa, D. Moissenet, H.V. Thien, M. Khedher, Virulence factors in Pseudomonas aeruginosa: mechanisms and modes of regulation, Ann. Biol. Clin. (Paris) 69 (2011) 393-403.

[20] C.E. Jensen, Spreading factors of bacterial origin, Acta Rheumatol. Scand. 3 (1957) 177-188.

[21] D.J. Hassett, L. Charniga, K. Bean, D.E. Ohman, M.S. Cohen, Response of Pseudomonas aeruginosa to pyocyanin: mechanisms of resistance, antioxidant defenses, and demonstration of a manganese-cofactored superoxide dismutase, Infect. Immun. 60 (1991) 328-336.

[22] G.J. Bonde, C.E. Jensen, A. Schmidt, In vitro and in vivo depolymerization of mucopolysaccharides by pyocyanine and a fluorescing green bacterial pigment, Acta Pharmacol. Toxicol. (Copenh) 13 (1957) 194-204.

[23] J. Duan, D.L. Kasper, Oxidative depolymerization of polysaccharides by reactive oxygen/nitrogen species, Glycobiology 21 (2011) 401-409.

[24] C. Campanac, L. Pineau, A. Payard, G. Baziard-Mouysset, C. Roques, Interactions between biocide cationic agents and bacterial biofilms, Antimicrob. Agents Chemother. 46 (2002) 1469-1474.

[25] T.P. Schaer, S. Stewart, B.B. Hsu, A.M. Klibanov, Hydrophobic polycationic coatings that inhibit biofilms and support bone healing during infection, Biomaterials 33 (2012) 1245-1254.

[26] J.A. Lichter, M.F. Rubner, Polyelectrolyte multilayers with intrinsic antimicrobial functionality: the importance of mobile polycations, Langmuir 25 (2009) 7686-7694.

[27] M.M. Fernandes, A. Francesko, J. Torrent-Burgués, F.J. Carrión-Fité, T. Heinze, T. Tzanov, Sonochemically processed cationic nanocapsules: efficient antimicrobials with membrane disturbing capacity, Biomacromolecules 15 (2014) 1365-1374

[28] K. Rahn, M. Diamantoglou, D. Klemm, H. Berghmans, T. Heinze, Homogeneous synthesis of cellulose p-toluenesulfonates in N,N-dimethylacetamide $\mathrm{LiCl}$ solvent system, Die Angew. Makromol. Chem. 238 (1996) 143-163.

[29] A. Francesko, L. Blandón, M. Vázquez, P. Petkova, J. Morató, A. Pfeifer, T. Heinze, E. Mendoza, T. Tzanov, Enzymatic functionalization of cork surface with antimicrobial hybrid biopolymer/silver nanoparticles, ACS Appl. Mater. Interfaces 7 (2015) 9792-9799.

[30] K.S. Suslick, M.W. Grinstaff, Protein microencapsulation of nonaqueous liquids, J. Am. Chem. Soc. 112 (1990) 7807-7809.

[31] A. Francesko, M.M. Fernandes, I. Perelshtein, E. Benisvy-Aharonovich, A Gedanken, T. Tzanov, One-step sonochemical preparation of redoxresponsive nanocapsules for glutathione mediated RNA release, J. Mater. Chem. B 2 (2014) 6020-6029.

[32] S. Amorim, R.A. Pires, D.S. da Costa, R.L. Reis, I. Pashkuleva, Interactions between exogenous FGF-2 and sulfonic groups: in situ characterization and impact on the morphology of human adipose-derived stem cells, Langmuir 29 (2013) 7983-7992. 
[33] I. Horcas, R. Fernández, J.M. Gómez-Rodríguez, J. Colchero, J. Gómez-Herrero, A.M. Baro, WSXM: a software for scanning probe microscopy and a tool for nanotechnology, Rev. Sci. Instrum. 78 (2007).

[34] D.J. Stickler, N.S. Morris, C. Winters, Simple physical model to study formation and physiology of biofilms on urethral catheters, Methods Enzymol. 310 (1999) 494-501.

[35] T.J. Halthur, U.M. Elofsson, Multilayers of charged polypeptides as studied by in situ ellipsometry and quartz crystal microbalance with dissipation, Langmuir 20 (2004) 1739-1745.

[36] B.F. Ozen, I. Weiss, L.J. Mauer, Dietary supplement oil classification and detection of adulteration using Fourier transform infrared spectroscopy, J. Agric. Food Chem. 51 (2003) 5871-5876.

[37] A. Rohman, Y.B. Che Man, Quantification and classification of corn and sunflower oils as adulterants in olive oil using chemometrics and FTIR spectra, Sci. World J. 2012 (2012) 1-6.

[38] J.M. Silva, A.R.C. Duarte, S.G. Caridade, C. Picart, R.L. Reis, J.F. Mano, Tailored freestanding multilayered membranes based on chitosan and alginate, Biomacromolecules 15 (2014) 3817-3826.
[39] L. Richert, P. Lavalle, E. Payan, X.Z. Shu, G.D. Prestwich, J.F. Stoltz, P. Schaaf, J.C. Voegel, C. Picart, Layer by layer buildup of polysaccharide films: physical chemistry and cellular adhesion aspects, Langmuir 20 (2004) 448-458.

[40] R.M. Donlan, Biofilms and device-associated infections, Emerg. Infect. Dis. 7 (2001) 277-281.

[41] T. Genco, L.F. Zemljič, M. Bračič, K. Stana-Kleinschek, T. Heinze, Physicochemical properties and bioactivity of a novel class of cellulosics: 6 deoxy-6-amino cellulose sulfate, Macromol. Chem. Phys. 213 (2012) 539-548.

[42] V. Gribova, R. Auzely-Velty, C. Picart, Polyelectrolyte multilayer assemblies on materials surfaces: from cell adhesion to tissue engineering, Chem. Mater. 24 (2012) 854-869.

[43] C. Picioreanu, J.U. Kreft, M. Klausen, J.A.J. Haagensen, T. Tolker-Nielsen, S. Molin, Microbial motility involvement in biofilm structure formation - a 3D modelling study, Water Sci. Technol. 55 (2007) 337-343.

[44] R.A. Al-Tahhan, T.R. Sandrin, A.A. Bodour, R.M. Maier, Rhamnolipid-induced removal of lipopolysaccharide from Pseudomonas aeruginosa: effect on cell surface properties and interaction with hydrophobic substrates, Appl. Environ. Microbiol. 66 (2000) 3262-3268. 